\title{
Bitiginal Communiations.
}

\section{THE STOMACH AND ITS AILMENTS PRAC- TICALLY ARRANGED.}

By W. S. OKe, M.D., Senior Physician of the Royal South Hants Infirmary.

[Real before the Southampton Medical Socicty, Nov. 7 th, 1858.] The subject of gastric disorders will be best handled by considering separately each morbid condition with which the stomach is liable to be affected. This will give us, at least, the most practical view of the symptoms, enable us to treat them with some degree of precision, and with the greatest probability of success. I propose, therefore, to treat the several morbid conditions of the gastric function under the following heads :The Neuralgic; the Arid; the Acid ; the Bilious ; the Inflated the Depraved; the Spasmodic; the Hæmorrhagic; the In fiamed; and the Cancerous. I do not mean to assert that each of these conditions will even generally be found uncom plicated and distinct. Doubtless some of them will often be associated with others: the neuralgic with the acid, and the acid with the bilious, or they may all co-exist. But even then there will probably be some prevailing symptoms which will sufficiently characterise the condition for practical purposes. Any attempt to effect such an arrangement (imperfect as it must necessarily be) will, I trust, be readily excused when it is considered how difficult it is to make any arrangement at all of the various morbid actions of an organ governed by the pneumo-gastric nerves, subjected to the mysterious functions of the sympathetics, and exposed to so many exfing causes both directly and indirectly.

Pemberton, who has left us one of the best practical works on the diseases of the abdominal viscera, when he comes to the stomach, writes as follows:- " The difficulties which present themselves when we reflect on a systematic arrangement of the diseases of the stomach, are so many and so great that the writer finds himself perpetually embarrassed to select and discriminate his materials with precision and perspicuity." Having made these observations in the way of preface, I shal at once proceed with my arrangement, which $I$ trust, will be found practical and useful.

\section{I.-Neuralgic Condition of the Stomach.}

This condition of the stomach has been termed gastralgia or gastrodynia. It more frequently occurs in women than in men, and for the most part in the middle period of life. It is characterised by severe aching pain of the epigastric region, which is rather relieved than aggravated by external pressure; the pain is generally brought on by food not easily digested, and especially by strong tea, and the pain continues without any abatement till the contents of the stomach have passed through the pyloric orifice into the duodenum, when it sub. sides. The patient is made conscious of this by an agreeable sensation of gurgling in the region of the duodenum and jejunum. The tongue is coated in the morning; the bowels are torpid, and the urine high-coloured, depositing the lithates. This condition of the stomach is often attended with the puking of clear watery fluid which, by some authors, is described as a distinct disease termed "pyrosis," or water-brash, but which is most probably caused by the gastric pain. The watery discharge may take place either before or after the taking of food, but more frequently afterwards; and it is singular that, in most cases, none of the food is brought up with it. As soon as the fluid is puked up the pain ceases, and the stomach remains comparatively easy until the next meal, when the pain and the watery puking return.

It is not decided from what source the watery fluid is derived. It is supposed by some to be secreted by the mucous glands of the stomach,-in the words of Pemberton, "from an altered and increased secretion of the glands of the mucous membrane," and when of a mucous character it may, and probably does, come from that source; but when the fluid is watery, might it not be supplied by the pancreatic glands, especially when it comes up in considerable quantities? The pancreatic duct empties itself into the second turn of the duodenum, side by side with the common bile duct; and if from the latter bile can be conveyed through the pylorus into the stomach, which is shown in bilious vomiting, why should not the pancreatic secretion, when the gland is abnormally excited, be conveyed there also? This is my opinion; which is, I think, strengthened by the symptoms accompanying the act of puking, viz. pain at the pit of the stomach, and a sense of constriction, as if the stomach were drawn to the back, which evidently points to the duodenum contracting upon its contents and propelling the increased secretion into the stomach. There is nothing forced in this statement; the pancreas is admitted to be a salivary gland; and as a severe neuralgic paroxysm of the alveolar branches of the fifth pair of nerves often causes an increased flow of salivary fluid into the mouth from the parotid, lingual, and submaxillary glands, so in like manner neuralgic pain of the gastric nerves may produce an increased secretion from the pancreatic gland into the duodenum, but in much larger quantities of course. It might be difficult to prove the fluid to be pancreatic by chemical analysis, because in the stomach it necessarily becomes mixed with the gastric secretions.

The proximate cause of functional gastrodynia appears to be a morbidly sensitive state of the villous coat of the stomach in its connexion, probably, with the pneumogastric nerve, because this nerve has sensitive and motor branches, and in that respect analogous with those nerve-fibres which are most liable to neuralgia in other parts of the body. Prout states " that an excess of acid, and particularly of the lactic, in the stomach is sometimes accompanied with gastrodynia, that is, rheumatic neuralgia, similar to that affecting other nerves of sensation." This, however, does not appear to be an exciting cause of the pain under consideration; because, though there may often be, and doubtless there is, an abnormal quantity of lactic acid present, the pain is seldom removed, or even mitigated, by the use of alkalies only.

Treatment. This morbid condition of the stomach in its early stages, is not difficult of cure. The bowels are to be first cleared by $a, b$, or $c$

a. R Hydrargyri chloridi gr. iij; pulveris rhei gr. $\mathrm{x}$; syrupi q. s. M. Fiat massa et divide in pilulas duas, hor somni sumendas ad secundam aut tertiam vicem.

b. R Pulveris rhei $\ni j$; magnesiæ sulphatis $3 \mathrm{ij}$; syrupi zingiberis, tincturæ jalapæ, àa $3 \hat{j}$; aquæ menthæ piperitæ $5 x$. M. Fiat haustus primo mane sumendus, post pilulas.

c. R Pilulæ hydrargyri, extracti colocynthidis compositi, $\bar{a} a \overline{~ g r}$. xxiv. Mlisce, et divide in pilulas xij, quarum sumantur ij alternis noctibus, ad tertiam vicem.

At the same time, a wineglassful of the infusion of hops may be taken every day at noon, as $(d)$, and, after the bowels have been sufficiently cleared, the quinine mixture $(e)$.

d. R Strobilorum lupuli jiij; aquæ ferventis zviij. Macera per horas quatuor, et cola.

e. R Quinæ disulphatis gr.ix; acidi sulphurici diluti guttas

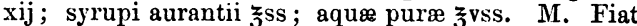
mistura cujus sumatur $\zeta_{j}$ omni mane, et meridie ante cibum.

If the pain be accompanied by watery pukings, the case will be more successfully treated with the nitrate of bismuth $(f)$, regulating the bowels with eight or ten grains of pulverised rhubarb every other night.

f. B Bismuthi nitratis, pulveris rhei, ãa $\bar{s}$ ss; liquoris cinchonæ $\tilde{3} \mathrm{j}$; aquæ puræ $\tilde{\mathcal{\jmath}} \mathrm{v}$. M. Fiat mistura cujus sumatur $z_{j}$ ter die.

The diet is to be light ard nutritious.

CASE I. Mary Head, aged 4l, had been for a long time suffering with severe aching pain of the stomach and watery pukings. The pain came on after meals, and never ceased till considerable quantities had been puked up. She complained also of headache, and was much attenuated. She was ordered to take a grain of calomel and four grains of the comp. colocynth pill every other night, and a dose of the bismuth mixture $(f)$ twice a day. Under this treatment the symptoms rapidly subsided, and in a few weeks she reported herself cured.

This case must be considered as representing many others of the same kind, which could be adduced, if it were necessary.

When the pain and pulings have continued for a length of time, the morbid sensibility of the mucous membrane becomes so augmented as to occasion the frequent vomiting of the food also, and the patient is reduced to great debility, extreme atrophy, and emaciation; such an aggravation will not yield to the above treatment alone, and requires more decided measures. I have met with some of such extreme cases; and the symptoms were so very similar to those of organic disease of the 
pylorus, as to render the diagnosis very difficult, till the result of the treatment proved that they were caused by disordered function only. The following is an instance of the kind.

CASE II. William Diaper, aged 24, a labourer, had been suffering vehement attacks of gastralgia for two years, for which he had been in a hospital, and under several medical men, without permanent relief. At the end of the year $I 845$, he was admitted a patient of the Southampton Dispensary under my eare. The pain of the epigastrium was of an aching character, extremely severe, came on generally after his dinner and caused him to vomit up his food, which was accompanied with a bitter or sour fluid; the urine was high coloured, the bowels were torpid, and the stools of a pale colour, showing that the hepatic function was also involved. From his long protracted sufferings and frequent vomitings, he was pale, exhausted, and emaciated to the last degree, in short, his aspect was such as to preclude all expectation of his recovery, from the probability that the case was that of organic disease of the pylorus. A blister was at once applied to the epigastric region, and ordered to be kept open; one of the pills $(g)$ to be taken every noon and night, and the bowels to be regulated with tifteen grains of rhubarb taken in the morning.

g. Bo Hydrargyri chloridi gr. xij; pulveris opii gr. vj; confec. tionis rosæ gr. $x x$. Misce et divide in pilulas $x i j$; quarum sumatur una omni meridie et nocte.

By these means the pain and vomiting gradually subsided, and then ceased. He then commenced the bismuth $(f)$, and continued it twice a day till his recovery was complete.

$f$. Bo Bismuthi nitratis, pulveris rhei, sing. $3 \mathrm{ss}$; acidi hy drocyanici diluti (Scheele) guttas vi; aquæ menthæ

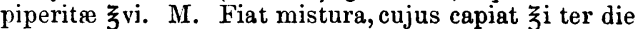

On the 30th of July, 1851, he called on me, and reported himself an able-bodied seaman in one of the Royal West India mail steam ships. He presented one of the most remarkable recoveries from severe gastrodynia I ever witnessed.

\section{II.-Arid on Dry Condition of the Stomach.}

Sometimes, instead of watery pukings, we meet with a dry condition of the whole of the mucous membrane of the mouth, the teeth, the tongue, the fauces, and, probably, of the cesophageal canal and stomach also. This case is of rare occurrence; indeed, I have seen but one instance during a long experience. Yet when it does occur, it appears of so distinet a character that I have deemed it right to rank it amongst the morbid conditions of the gastric functions. The case alluded to is so well marked, that the symptoms and method of cure will be best manifested by describing it.

CASE III. C. Coates, a gamekeeper, married, aged 58, and of very stout form, consulted me in May 1835, for an abnormal and distressing dryness of the mouth, teeth, internal fauces, and pharynx, which had continued for two months, and it was accompanied with a sense of weight at the chest and drowsiness. The mucous membrane of the palate and cheeks was like dried leather, and without the slightest trace of any moisture whatever. The teeth shone with dryness; the tongue felt stiff, as if it would break, and was as dry as a board. There was neither fever nor thirst, nor was the general health much impaired, but the entire surface of the skin was deficient in vascularity, hypertrophied, and studded with elephantiasis tubercles, varying in size from that of a pea to that of a walnut.

The indication of cure in this case was to set free the obstruction of the cutaneous function, which was probably the cause of the internal dryness. With this view, I ordered the patient to take two grains of ipecacuanha every four hours, to produce vomiting and relax the skin. This effect was produced the liver disgorged a large quantity of dark coloured bile; the salivary secretion was restored; and the dryness was permanently removed.

\section{III.-Acid Condition of the Stomach.}

The acid condition of the stomach is more commonly met with than any other. It has been termed cardialgia, or heartburn, and is characterised by a sense of burning heat about the cardiac orifice, a feeling of weight or uneasiness at the epigastrium after meals, flatulent and acid eructations with rumination of the food, and irregularity of the heart's action; the tongue is furred in the morning; the urine scanty and high coloured, depositing the lithates in a yellow lateritious sediment; the bowels are inactive; the stools are either of a pale or dark colour; and the sleep is disturbed by dreams, startings, or cramps of the muscles of the lower limbs. There is no febrile disturbance, and the appetite is but little diminished.
Persons exhibiting this group of symptoms have usually a sallow complexion, are not well nourished, and are sulject to various cutaneous eruptions, especially of an acnoid kind; they are subject also to facial and dental neuralgia, and also to gout, if predisposed to that disease. The acids found in the stomach (according to Prout) are derived from two sources, either from the blood circulating in the vessels supplying the stomach, or from changes occurring in the matters secreted in those vessels, and also from the alimentary matter taken into the stomach. The same author states, that the lactic and muriatic acids are principally derived from the blood; and that the oxalic, butyric, acetic, and carbonic acids are derived from the food during imperfect digestion. If this be correct, it follows that the two former acids are necessary to the process of gastric assimilation, and that the four latter are the result of the decomposition of food. The proximate cause of this morbid condition will probably be found in a disturbance or deficiency in the secreting forces of the villous function; the former is temporary, and produced by occasional errors in diet the latter is of a more permanent character, and brought on by the constant spplication of exciting cruses, such as the habit of indulging in smoking and drinking to excess-short, perhaps, of actual intoxication, yet sufficient, by daily repetition, to damage the digestive powers for life; and should the habit (as it often unhappily does) become inveterate, it will soon involve the structure of the liver in organic disease, and terminate in dropsy and death.

Sometimes the acidity, from inattention to diet, becomes so intense as to occasion a sudden and violent sympatbetic action of the heart, that greatly alarms the patient, and threatens to terminate his life. By abstaining from intemperate habits, and by carefully observing a proper diet, the formation of morbid acid might in great measure be prevented; but any inattention in this respect will soon reproduce it, and convince the transgressor that indiscretion as to diet cannot be practised with impunity.

These facts clearly shew the necessity, on the part of parents, of establishing in their children a habit of temperance, that, as they adolesce, the vigour of the constitution may be normally and fully developed. To suppose that the daily allowance of wine, or any such stimulant, is necessary to support the strength of the constitution, is simply absurd. The very contrary is proved by the fact that the physical powers of the strongest animals in the creation-the elephants, for example-are upheld, as to their drink, by water only.

How often does the medical man see this terrible and too prevalent habit of drinking to excess undermine and cast down, in the meridian of life, robust constitutions, which, by temperance, might have enjoyed the blessing of health to good old age! 'There may be, perhaps, many addicted to this fascinating vice consoling themselves with the fact that there are hard drinkers who attain a very advanced age, and who have escaped these predicted evils; but, according to my observation, these are but mere exceptions to the general rule of ineapacity both of body and mind, and premature death. I will venture to affirm that, of one hundred regular hard drinkers, not more than five shall be found to exceed the age of fifty years, supposing the whole to have commenced the habit at the age of twenty years. In the course of my practice, I have had considerable experience in endeavouring to arrest the haibit of drinking, by faithfully stating its fatal consequences; but I confess that a very small amount of succes has attended my efforts. The next best thing to be done is to prevent the habit; and, in order to effect this, the temperance societies appear to be doing great service to the com munity. They deserve, therefore, to be encouraged as much as possible.

Treatment. If the gastric acidity be produced by occasional errors of diet, the functions of the stomach may be corrected by the aperients $(a),(b)$, or $(c)$.

a. B Pilulæ hydrargyri, pulveris rhei, $\bar{a}$ gr. xxiv ; syrupi q. s. Misce et divide in pilulas xij. Capiat duas alternis noctibus.

b. R Magnesiæ sulphatis $3 \mathrm{vj}$; magnesiæ carbonatis 3 iss ; acidi hydrocyanici diluti (Sch.) guttas vj; syrupi zin. giberis $\zeta_{s}$; aquæ menthæ piperitæ ad vj. M. Fiat mistura cujus sumantur cocblearia larga duo omni mane et meridie ex aquæ tepidæ pauxillo.

c. B Sodæ bicarbonatis $3 j$; sodæ sulphatis $3 \mathrm{vj}$; tincturæ cardamomi compositæ, aquæ cinnamomi, â $\overline{s s}$; spiritûs ammoniæ aromatici Эiss; aquæ destillatæ ad そvj. M. Fiat mistura, cujus bibat quartam partem omni mane et meridie ante cibum. 
If the acidity should have continued long, and be the result of a morbid action of the secerning capillaries, a more gradual treatment will be required to correct it, as $(d)$ and $(e)$.

d. Bo Hydrargyri chloridi gr. iij; pulveris ipecacuanhæ gr. vj; extracti conii gr. xij; aloës extracti aquosi gr. xij; syrupi q. s. Divide massam in pilulas xij æquales, quarum sumatur i ter die cum hâc dosi.

e. Potassæ bicarbonatis $Э \mathrm{\exists j}$; acidi citrici gr. $\mathrm{xv}$; liquoris potassæ $m x$; acidi hydrocyanici diluti (Scheelii) $\mathrm{mj}$; syrupi aurantii $3 j$; aqua ad 3 iss. Misce.

When the acidity has been corrected by the above means, improvement may be maintained by $(f),(g)$, or $(h)$.

$f$. R Pilulæ hydrargyri gr. xij; piluæ rhei compositæ $Э \mathrm{j}$; pulveris ipecacuanhæ gr. iij. Misce et divide in pilulas vj, quarum sumatur una omni nocte alternâ vel tertiâ.

g. R Sodæ bicarbonatis $3 \mathrm{j}$; liquoris potassæ $3 \mathrm{j}$; spiritús ammoniæ aromatici $3 \mathrm{ij}$; tincturæ gentianæ compositæ $3 \mathrm{iij}$; aquæ menthæ piperitæ ad $\xi \mathrm{vj}$. M. Capiat $\zeta_{j}$ omni meridie et nocte.

h. B Liquoris hydrargyri bichloridi, tincturæ cardamomi compositæ, à 3 iij; aquæ menthæ piperitæ ad $\zeta v j$. Misce. Capiat $\mathbf{j}$ omni meridie et nocte.

Vel B Sodæ carbonatis exsiccatæ, pulveris rhei, a 3 ss; liquoris potassæ q. s. Fiat massa in pilulas xij dividenda, quaram capiat duas meridie et nocte.

Rhubarb is undoubtedly the best aperient to correct disorders of the gastric function.

Pemberton, when the alkaline treatment failed, employed with success the mineral acids, of which he prefers the nitric. "It is probable", he says, " that the salutary effect observed from the use of mineral acids in this condition of the stomach may arise from their property of interrupting morbid fermentation. .. As the acid in a stomach predisposed to generate it is constantly forming it, it is necessary that the remedy should be frequently applied: we may, therefore, give five drops of the nitric acid every four hours in cold water, by which the stomach can be kept constantly under its influence." The same mode of treatment is recommended by Heberden in his Commentaries. "Feminæ quædam dum ventrem fervet, gravissime inflictabantur cum hoc malo, adversus quod, cum remedia consueta nihil proficissent, acidum vitriolicum tentatum est, et brevi illud sanavit."

It has been stated that great violence in the heart's action is sometimes occasioned by gastric acidity. The following is a case of the kind. A medical gentleman, having been exposed to severe cold several hours in an open carriage, on his return home, late at night, drank some strong coffee, and ate a buttered roll; after which, having drank some brandy and water, he smoked a cigar, and retired to bed. In a few hours, he felt a burning acidity at the cardiac region, which was followed by a most vehement action of the heart, that greatly alarmed him, and made him exclaim that he was abont to die! As soon as possible, a full dose of the bicarbonate of soda was given him, which relieved the stomach, and gradually moderated the heart's action; but a hyperaction of the organ, accompanied by sleepless nights, continued to harass him for many months, till at length, by a strict attention to his diet, suitable medicines, and a change of air, the morbid action of the heart subsided, and his natural sleep was completely restored; but, though thirty years have expired since the attack, the same predisposition to acidity remains, and prevails as often as the stomach is subjected to the same exciting causes.

This condition of the stomach, associated, as it often is, with a disorder of the hepatic function (as evidenced by dark acrid secretions), sometimes produces such a morbid sensibility of the nervous system, in some constitutions, as to give rise also to idiopathic tetanus. The following case, to which I was called in consultation some years ago in this town, appeared to be derived from this cause.

CASE IV. Theodore Cross, 8 years of age, of light coloured hair and fair complexion, had been generally healthy from his birth. On the 12th of September, 1838, when he was about to eat his breakfast, he found that he could not open his mouth ; and this inability continued the three following days, except that the jaws could be sufficiently separated to admit of spoondiet. Up to the 15th, no other symptom was noticed by his parents. On this day, his mother gave him two drachms of Epsom salts at 9 o'clock, A.M., which operated at $11 \cdot 30$, when the first tetanic spasm took place; and it was so violent as to throw him off the night-table. The salts acted only once, and the stool was costive and of a dark colour. He slept badly the following night; and, on the 16th, complained of severe pain across the forehead, which was accompanied with a profuse perspiration. In the evening, the tetanic spasm returned, which so stiffened the whole of the body as to prevent his being placed in the sitting posture. From this date the tetanic rigidity continued, and was always aggravated and increased by the slightest touch on any part of the surface of the body. His mother kissing his lips would bring on the spastic rigidity at any time. I saw him on the $23 \mathrm{rd}$, in consultation, eleven days from the commencement of the disease; and found his jaws almost losked, and his whole body stiff and inflexible. On placing my hand upon the epigastrium, a violent involuntary spasm was instantly produced, and the greater part of the muscles (especially those of the limbs) were straightened and stiffened into the hardness of board. Up to this time he had been treated with calomel and morphia at bedtime, and with the sesquioxide of iron at intervals during the day, without producing sleep, or any other benefit whatever. As nothing had passed the bowels for ten days, two grains of calomel were ordered every two hours, in syrup, which he was enabled to suck betwixt the incisors, and to swallow, for the power of deglutition was not wholly lost; and, as he was feverish, he was directed to suck in currant jelly dissolved in water ad libitum, which was extremely grateful to him. This treatment alone was persisted in from the $23 \mathrm{rd}$ to the $26 \mathrm{th}$, when the bowels began to act copiously, and continued to do so all that day and the following night, discharging dark fæeal matter. In the morning, he was quite exhausted, fell into a deep sleep at ten o'clock, and did not awake till five in the evening. It was evident that he was greatly relieved. The whole of the tetanic spasms had subsided, and he was able to open his jaws and take fluid nourishment.

He continued to progress from day to day, the spasms only returning once now and then, without distressing him. In order to restore his strength, for he had been without nourish. ment from the fifteenth, he drank milk freely, which agreed with him well. His nervous system was strengthened with the susquioxide of iron, the bowels were kept soluble by castor oil, and on the 31st of September he was pronounced cured.

Reflecting on this very interesting case, it appears that the tetanic spasms were the result of a reflex action of the spinal motor nerves, originated by some irritation of those fibrillæ of the ganglionic nerves which supply the gastric and hepatic functions, and the irritating cause may reasonably be referred to this morbid condition of the stomach.

In this condition of the stomach, as has been before observed, a suitable diet must be observed, or medicine will be taken in vain. It should consist of mutton, roast, boiled, or broiled; poultry, eggs, plain light pastry, with well cooked fruit, and farinaceous vegetables well boiled. The beverage least likely to turn acid is sound bottled porter. All food tending to cause acidity is to be avoided, such as butter, fat meats, fish, rich sauces and soups, lard cakes, suet puddings, and rich nastries, together with home-made wines and beer. On the subject of gastric acidity, Heberden in his Commentaries has the following passage: "Lac, olus, piscis, pinguia omnia acido ventriculo parvum conveniunt et acorem augent.' '

[To be continued.]

\section{FATAL CASE OF TRAUMATIC GANGRENE.}

By R. U. WEST, M.D., Alford, Lincolnshire.

WILLIAM HaLL, aged 47, the manager of a steam-threshing machine, a man of florid complexion, stout and healthy, a free liver, never intoxicated, but taking regularly four pints of ale daily, was walking home from his work on Tuesday evening, January 25 th. At 7 o'clock, the night being very dark and windy, so that it was difficult to either see or hear anything, a young farmer, riding carelessly "at a swinging canter" by the side of the road, met this man and rode him down. He was taken up and carried home, about half a mile further. $\mathrm{He}$ had sustained a compound fracture of the right leg about three inches above the instep. Although he was bleeding freely, his friends did not send for professional aid until the next morn. ing, when the young farmer. who had been the unfortunate cause of the accident, sent a "bone-setter" to him. 'This man, on seeing the nature of the injury, contented himself with placing the wounded limb on a cushion, and applying some strips of adhesive plaister on the external wound, and then threw up the case. I was then sent for, and saw the poor man at about noon, on the Wednesday, the day after the accident. I found a compound fracture of the tibia and fibula; the flesh 